\title{
LA JUSTICIA RESTAURATIVA EN LA EJECUCIÓN PENITENCIARIA
}

\author{
Florencio de Marcos Madruga \\ Magistrado, Profesor asociado en la Universidad de Valladolid \\ Title: Restorative Justice in the serving of the sentence
}

Resumen: La participación de la víctima en la fase de ejecución del proceso penal en nuestro ordenamiento es un hecho novedoso que, más allá de la reparación civil, arranca del Estatuto de la víctima en el año 2015, el cual introduce la Justicia restaurativa en ese momento procesal. Este instrumento puede ser una importante alternativa o complemento a la justicia tradicional en aras de lograr una mejor satisfacción de los intereses de la víctima. Siendo este el objetivo, se viene desarrollando desde el año 2019 una experiencia en el CIS «Máximo Carrera» de Valladolid en la cual se trabaja con liberados condicionales, penados clasificados en tercer grado y condenados a la pena de trabajos en beneficio de la comunidad, con el objetivo de elaborar un protocolo de actuación extensible a otros centros.

Palabras clave: Justicia Restaurativa; Víctima; Victimario; Encuentro restaurativo; Juzgado de Vigilancia Penitenciaria; Mediador.

Abstract: The participation of the victim in the execution phase of the criminal process in our legal order is a novel fact that, beyond civil reparation, stems from the 2015 Statute of the victim, and introduces Restorative Justice within that procedural moment. This instrument may become an important alternative or complement to traditional Justice in order to achieve a better satisfaction of the interests of the victim. A Program dealing with inmates subject to conditional parole, convicts classified in third degree and sentenced to community services has been developed in the CIS «Máximo Carrera» of Valladolid since 2019, with the aim of drawing up an action protocol that may be extended to other prisons.

Keywords: Restorative Justice; Victim; Offender; Restorative Encounter; Penitentiary Surveillance Judge; Mediator. 
Sumario: 1 . La víctima en la fase de ejecución de la pena privativa de libertad. - 2. La Justicia restaurativa como cauce de participación de la víctima. - 3. Marco normativo. - 4. Contenido del programa piloto. - 4.1. Operadores. - 4.2. Fases. - 4.2.1. Fase de responsabilización por el delito cometido. - 4.2.2. Fase de reparación y de encuentro con la víctima del delito. - 4.2.3. Encuentro restaurativo y demás opciones. - 4.3. Resultados de la primera edición. 5. Conclusiones. -5.1 . Ventajas. - 5.2. Déficits. -6 . Bibliografía.

\section{La víctima en la fase de ejecución de la pena privativa de libertad}

La introducción de los procesos de justicia restaurativa en la fase de ejecución penal, especialmente de la pena privativa de libertad, conecta con el nuevo papel que se va a dar a la víctima en aquel proceso; posición que conecta tanto con la crisis de la concepción tradicional del Derecho penal, como con una cierta utilización populista de la política criminal ${ }^{1}$.

En la contraposición del postulado represión del delito y tutela jurídica frente a la reparación de la víctima, esta última habría venido ocupando un rol secundario, mas, sin embargo, en la actualidad se aspiraría a mejorar la posición de esta última una vez superadas las exigencias mínimas del proceso debido cara al infractor ${ }^{2}$.

En el caso español, el papel de la víctima en la fase de ejecución habría sido cuando menos escaso, no habiendo tenido aquélla la consideración de parte por entenderse que el ejercicio del ius puniendi en la fase ejecutiva sería una prerrogativa exclusivamente pública, no ostentando un interés legítimo en su desarrollo, pues si el fin primordial de la pena privativa es la reeducación y la reinserción, art. $25 \mathrm{CE}$, la víctima en tanto al logro de tal objetivo resocializador sería un aliud, sus expectativas e intereses serían otros ${ }^{3}$.

Con anterioridad a la Ley 4/2015, de 27 de abril, del Estatuto de la vícti$m a$, sin alcanzar la consideración de parte procesal, sí se recogía en el ámbito del adelantamiento de la libertad condicional — hoy en día, el art. 90.2 $\mathrm{CP}^{-4}$ y en el procedimiento de exoneración de los periodos de seguridad -arts. 36 y $78 \mathrm{CP}$-, con una notoria imprecisión técnica-terminológica,

1 G. Landrove Díaz, La moderna Victimología, Valencia, Tirant Lo Blanch, 1998, p. 13; A. GIL GIL, «Sobre la satisfacción de la víctima como fin de la pena», Indret: Revista para el Análisis del Derecho, $\mathrm{n}^{\circ}$ 4, 2016.

2 H. Soleto MuÑoz, «La justicia restaurativa, mecanismo adecuado para mejorar la reparación a la víctima en el proceso penal», Justicia Restaurativa y mediación penal, Cuadernos Digitales de Formación, CGPJ, n 17, 2017, p. 2.

3 Sería claro ejemplo de esta concepción el ATC 373/1989.

4 Esta audiencia a las demás partes en el adelantamiento de la libertad condicional se introduce con la reforma del art. 91 CP hecha por la LO 7/2003. 
la necesidad de dar audiencia a lo que se va a denominar demás partes. Partes ante el Juez de Vigilancia Penitenciaria lo eran exclusivamente el Ministerio Fiscal y el interno/liberado, con lo cual esa mención habría que ponerla en conexión con la fase del proceso penal anterior a la ejecución, esto es, quienes fueron parte en la fase de enjuiciamiento, acusación particular y popular. Pero oír no atribuye una posición procesal de tal empaque que comprenda la potestad de formular recursos, que, en definitiva, sería el auténtico acto de empoderamiento de la víctima.

Esta consideración de la audiencia a las demás partes se recoge también desde la LO 5/2010 en el procedimiento de revisión ante el sentenciador de las medidas de seguridad privativas de libertad.

Es con la Ley 4/2015 cuando se va a dar, con relación ciertas tipologías y siempre y cuando se trate de penas de prisión de más de cinco años, la cualidad de parte a la víctima, tanto en el procedimiento de exoneración de los periodos de seguridad —no en la concesión del tercer grado, que sigue siendo campo exclusivo de la Administración-, como en la concesión de la libertad condicional en tales supuestos. Con esta nueva posición, la víctima va a ser, no solo oída, antes bien, va a poder cuestionar la eventual decisión judicial a través del correspondiente recurso. La justificación del nuevo diseño legislativo se recoge en la Exposición de Motivos de esta norma cuando se afirma que el «Estado, como es propio de cualquier modelo liberal, conserva el monopolio absoluto sobre la ejecución de las penas, lo que no es incompatible con que se faciliten a la víctima ciertos cauces de participación que le permitan impugnar ante los Tribunales determinadas resoluciones que afecten al régimen de cumplimiento de condena de delitos de carácter especialmente grave» 5 .

No se trata doctrinalmente de una cuestión pacífica, pues frente a las posturas favorables ${ }^{6}$, cabe invocar, además del argumento de la falta de compulsión alguna por la normativa europea ${ }^{7}$, que con este planteamiento se condena a la propia víctima a la pena de prisión al hacer perpetuar las necesidades de venganza durante la duración de aquélla, amén de no

5 Se trata de una mera opción legislativa, tal y como puso de relieve el voto particular al Informe del CGPJ sobre el Anteproyecto, no siendo exigencia alguna derivada de la normativa europea, Directiva 2012/29/UE del Parlamento Europeo y del Consejo, de 25 de octubre de 2012, por la que se establecen normas minimas sobre los derechos, el apoyo y la protección de las víctimas de delitos, ni tampoco tiene parangón en Derecho comparado o jurisprudencia de los Tribunales europeos al efecto.

6 El Informe de la Fiscalía General del Estado de 14 de noviembre de 2013 justifica la intervención de la víctima en esta fase del proceso penal en atención del elemento prevencionista o retributivo de la pena privativa de libertad.

7 F. RENART GARCÍA, «Del olvido a la sacralización. La intervención de la víctima en la fase de ejecución de la pena (Análisis del art. 13 de la Ley 4/2015, de 27 de abril, del Estatuto de la víctima del delito, a la luz de la L.O. 1/2015, de 30 de marzo, de modificación del Código Penal)», Revista Electrónica de Ciencia Penal y Criminología, n 17-14, 2015, p. 4. 
resulta justificada la intervención porque el Derecho penitenciario tiene que estar orientado a la reinserción ${ }^{8}$.

En esta línea se ha postulado, tras reconocerse la necesidad de la reforma para reforzar el papel a la víctima en el proceso penal, que el cauce no tiene por qué ir encaminado por la vía de la construcción de un obstáculo a la reinserción, antes bien, por la vía restaurativa y no vindicativa ${ }^{9}$.

\section{La Justicia restaurativa como cauce de participación de la víctima}

La justicia restaurativa es un cambio de ciento ochenta grados con respecto a la relación de la víctima y el Estado. Supone una profunda revisión de la mentalidad tradicional sobre la función del sistema penal y los modos de afrontar las situaciones creadas por el delito; en definitiva, un auténtico cambio de paradigma que toma de referencia la idea del fracaso del modelo actual y la necesidad imperiosa de acudir a una alternativa $^{10}$.

Elementos de justicia restaurativa estarían ya presentes en el Antiguo Testamento, en el Libro de Amós (Am 9,11-15), y en los Evangelios (Mt 5,6) ${ }^{11}$.

La proyección de la justicia restaurativa en el proceso penal va más allá de la concepción meramente cuantitativa de la justicia penal, ese entendimiento de que sus intereses, los de la sociedad en definitiva, se saldan con la imposición de una pena de mayor o menor entidad, y se sumerge en lo cualitativo, en la focalización en la posición de la víctima, sus necesidades e inquietudes, que no tienen imperiosamente que coincidir con el afán vindicativo, ni se ven atendidos por la mera retribución que conlleva el castigo al infractor. No significa el abandono de los tradicionales valores del proceso penal, los derechos del encausado, ni de los fines de la pena íntimamente ligados a la colectividad, sino un nuevo punto de vista que opere como complemento en el sistema y que haga resurgir a la Justicia como una ayuda a quien se ha visto dañado por el delito. No se trata ya de la atención de lo meramente económico, que

8 M. Acale SÁnchez, «Terrorismo, delincuencia organizada y sistema de penas», en P. Faraldo Cabanas (dir.), L.M. Puente Alba y J.A. Brandariz García (coords.), Nuevos retos del Derecho Penal en la era de la globalización, Valencia, Tirant Lo Blanch, 2004, p. 349.

9 M.J. Castañón Álvarez y M.P. Solar Calvo, «Estatuto de la víctima: consideraciones críticas a la nueva Ley 4/2015», Diario La Ley, nº 8685, 2016.

10 T. Armenta Deu, «Justicia restaurativa, mediación penal y víctima. Vinculación europea y análisis crítico», Revista General de Derecho Europeo, no 44, 2018, p. 206.

11 J.L. Botero Martínez, "Justicia restitutiva, retributiva y estructural en el contexto de la profecía bíblica», Reflexiones Teológicas, n 10, 2012, pp. 64-45 y 68-69. 
siempre ha estado presente en nuestro proceso, antes bien un instrumento de canalización de las inquietudes y miedos, del propio sufrimiento y tensión, en definitiva, de quien injustamente ha padecido la lesión de sus bienes y derechos. Se conforma así la justicia restaurativa como una vía posible de esa frustración que padece la víctima y que hasta ahora no ha tenido respuesta y apoyo alguno con las formas procesales tradicionales; esto es, estamos ante un modo de ver el conflicto de intereses que implica el delito de una forma distinta y que lleva a un proceso de calidad para superar aquél, no solo teniendo en cuenta la sociedad como ente abstracto, como concepto contrapuesto al individuo, sino potenciando la posición de este último y la especificidad de él. Si la justicia es algo humano, instrumento de solución de conflictos, aquél se desarrolla y tiene lugar entre sujetos concretos, aunque medie un trasfondo de defensa social, por lo cual éste es ahora un modo de traer al primer plano a uno de sus miembros concretos: la víctima.

De esta forma, la reparación a la víctima puede ir más allá de la propia medida penal o la indemnización a cargo del condenado o la compensación a cargo del Estado y puede consistir en compensaciones no económicas relacionadas con la actitud del agresor, la cual es susceptible de producirse cuando la víctima participa en un procedimiento de justicia restaurativa, cuyos objetivos son respecto de la víctima la reparación o resarcimiento del daño, la recuperación del sentimiento de seguridad - como forma de reparación simbólica-, y la resolución de problemas asociados a la victimización secundaria derivados de la reiterada llamada al proceso del ofendido como testigo. Cabe afirmar que esta conceptuación de la justicia restaurativa se conforma como un sistema complementario al de la justicia procesal en el cual la recuperación de la víctima como sujeto con necesidades que, sin dejar de lado la posibilidad de la reparación económica, van más allá de ella o de las reivindicativas ${ }^{12}$.

\section{Marco normativo}

En el plano internacional, hay que hacer una primera mención, en el seno de Naciones Unidas, a la Resolución 2002/12, del Consejo Económico y Social, sobre Principios básicos para la aplicación de programas de justicia restaurativa en materia penal -la cual tendría como precedentes la Resolución 1999/26 de 28 de julio de 1999, sobre Elaboración y aplicación de medidas de mediación y justicia restaurativa en materia de justicia penal-, en la que aquél pidió a la Comisión de Prevención del Delito y Justicia Penal que estudiara la conveniencia de formular normas de las

12 H. Soleto MuÑoz, «La justicia restaurativa, mecanismo adecuado para mejorar la reparación a la víctima en el proceso penal», Justicia restaurativa y mediación penal, Cuadernos Digitales de Formación, CGPJ, nº 17, 2017, p. 10. 
Naciones Unidas en materia de mediación y justicia restaurativa; y la Resolución 2000/14 de 27 de julio de 2000, sobre Principios básicos sobre la utilización de programas de justicia restaurativa en materia penal, en la que el Consejo pidió al Secretario General que solicitara observaciones de los Estados miembros y de las organizaciones intergubernamentales y no gubernamentales pertinentes, así como de los institutos que integran la red del Programa de las Naciones Unidas en materia de prevención del delito y justicia penal, sobre la conveniencia y los medios de establecer principios comunes para la aplicación de programas de justicia restaurativa en materia penal, incluida la conveniencia de elaborar un nuevo instrumento con ese fin.

Ya la Declaración sobre los principios fundamentales de justicia para las víctimas de delitos y del abuso de poder, adoptada por la Asamblea General en su Resolución 40/34, de 29 de noviembre de 1985, amén de recoger un cúmulo de directrices orientadas a preservar el papel de la víctima y que la justicia no se constituya en un nuevo elemento de victimización, recoge en el apartado séptimo que «se utilizarán, cuando proceda, mecanismos oficiosos para la solución de controversias, incluidos la mediación, el arbitraje y las prácticas de justicia consuetudinaria o autóctonas, a fin de facilitar la conciliación y la reparación en favor de las víctimas».

La Resolución 2002/12, en su Preámbulo, renueva su apuesta por la justicia restaurativa en cuanto instrumento configurado como respuesta evolutiva al delito que respeta la dignidad y la igualdad de todas las personas, favorece el entendimiento y promueve la armonía social mediante la recuperación de las víctimas, los delincuentes y las comunidades, permitiendo a los afectados por un delito compartir abiertamente sus sentimientos y experiencias, teniendo por objeto atender sus necesidades. Tal enfoque tendría una triple proyección, pues por un lado daría a las víctimas la oportunidad de obtener reparación, sentirse más seguras e intentar cerrar una etapa; por otro, permite a los delincuentes comprender mejor las causas y los efectos de su comportamiento y asumir una genuina responsabilidad; y, por último, permite a las comunidades comprender las causas profundas de la acción delictiva, promover el bienestar comunitario y prevenir la delincuencia.

De esta forma, se afirma que la justicia restaurativa es una respuesta evolutiva al delito que respeta la dignidad y la igualdad de todas las personas, favorece el entendimiento y promueve la armonía social mediante la recuperación de las víctimas, los delincuentes y las comunidades.

En su apartado segundo se define qué se entiende por proceso restaurativo, que sería «todo proceso en que la víctima, el delincuente y, cuando proceda, cualesquiera otras personas o miembros de la comunidad afectados por un delito, participen conjuntamente de forma activa en la resolución de cuestiones derivadas del delito, por lo general con la ayuda de un facilitador». 
Por otro lado, la anterior formulación admite diversas opciones, pues dentro de ella cabe «la mediación, la conciliación, la celebración de conversaciones y las reuniones para decidir condenas».

Del propio modo, el resultado susceptible de alcanzar tampoco es unívoco, antes bien permite múltiples fórmulas, como son la reparación, la restitución y el servicio a la comunidad encaminados a atender a las necesidades y responsabilidades individuales y colectivas de las partes y a lograr la reintegración de la víctima y del delincuente.

Es llamativo que el objetivo es dual, pues, aunque la implementación de la justicia restaurativa tiene como protagonista a la víctima, al tiempo, aquélla se pone en conexión con la finalidad resocializadora de las penas recogida en las Reglas mínimas 58 y 65, de la versión vigente al tiempo de la Resolución analizada ${ }^{13}$. Tal principio reinsertador, hoy en día, se corresponde con el apartado 91 de la Reglas Nelson Mandela.

En el ámbito europeo, Consejo de Europa, en las Reglas Penitenciarias Europeas ${ }^{14}$, que establecen unos principios comunes relativos a política penitenciaria en ese marco con relación a los penados, se recoge, en la número 103.7, que los internos que lo deseen «podrán participar en un programa de Justicia reparadora y reparar las infracciones que han cometido».

La Recomendación CM/Rec (2018) 8 del Comité de Ministros del Consejo de Europa a los Estados miembros en materia de justicia restaurativa penal ${ }^{15}$, parte de reconocer los beneficios de la justicia restaurativa con respecto a los sistemas judiciales penales, los avances realizados en los Estados miembros en cuanto a la aplicación de aquélla como proceso de resolución de problemas, flexible, receptivo y participativo y que ella puede complementar los procesos penales tradicionales o puede aplicarse como alternativa a estos. Entiende además que se trata de un método a través del cual las necesidades e intereses de las partes pueden ser identificados y satisfechos de una manera equilibrada, justa y colaborativa, pues la reparación del daño causado por el delito puede requerir una respuesta que va más allá de la mera sanción penal. Perspectiva que comprendería como partes interesadas en abordar y reparar el daño causado por el crimen, no solo a la víctima y victimario, sino otros posibles ofendidos y la propia comunidad. Instrumento que además inculcaría un sentido de responsabilidad en le ofensor y una oportunidad para aquél en orden a compensar el daño causado.

13 Adoptadas por el Primer Congreso de las Naciones Unidas sobre Prevención del Delito y Tratamiento del Delincuente, celebrado en Ginebra en 1955, y aprobadas por el Consejo Económico y Social en sus resoluciones 663C (XXIV) de 31 de julio de 1957 y 2076 (LXII) de 13 de mayo de 1977.

14 Recomendación CM/Rec (2006) 2.

15 Adoptada por el Comité de Ministros el 3 de octubre de 2018 en la 1326a reunión de los Delegados de los Ministros. 
Define dicho texto la justicia restaurativa como aquel proceso que permita a aquellas personas dañadas por el delito y a las personas responsables del daño a participar activamente, si dan su consentimiento libremente para ello, en la resolución de las consecuencias resultantes del delito, con la ayuda de un tercero independiente y cualificado - facilitador- Al tiempo se afirmaría que consistiría en un diálogo, ya sea directo o indirecto, entre la víctima y el ofensor, aunque también puede implicar, si procede, a otras personas afectadas por un delito directa o indirectamente.

En el espacio ya de la Unión Europea, hay que mencionar la Directiva 2012/29/UE del Parlamento Europeo y del Consejo, de 25 de octubre de 2012, por la que se establecen normas mínimas sobre los derechos, el apoyo y la protección de las víctimas de delitos y por la que se sustituye la Decisión Marco 2001/220/JAI del Consejo. En dicha norma se reconoce que el delito es un injusto contra la sociedad y una violación de los derechos individuales de las víctimas y por ello las víctimas de los delitos deben ser reconocidas y tratadas de manera respetuosa, sensible y profesional, sin discriminación de ningún tipo, tener en cuenta su situación y necesidades, sin que se produzca victimización secundaria, ni intimidación o represalias, debiéndoseles reconocer un apoyo suficiente para su recuperación y contar con un acceso suficiente a la justicia.

La Directiva hace una especial llamada a la necesidad de implantación de instrumentos de justicia restaurativa, fijando las líneas fundamentales de aquéllos en el art. 12. Se perfilan así lo servicios de justicia reparadora para aquellas víctimas que opten por participar en tales procesos, fijándose como condiciones mínimas:

a) Que redunden en interés de la víctima atendiendo a consideraciones de seguridad.

b) Que se basen en el consentimiento libre e informado de la víctima, la cual podrá retirarse en cualquier momento; información exhaustiva e imparcial sobre el mismos y sus posibles resultados, así como sobre los procedimientos para supervisar la aplicación de todo acuerdo.

c) Que el infractor haya reconocido los elementos fácticos básicos del caso.

d) Todo acuerdo debería ser alcanzado de forma voluntaria y ser tenido en cuenta en cualquier otro proceso penal.

e) Confidencialidad y no publicidad de los debates, salvo cuerdo de las partes o interés público superior conforme a la norma nacional.

Se trata de un punto de vista totalmente distinto al que se adopta habitualmente en la justicia penal. Aquí el centro de gravedad está en la víctima, en su interés, si el proceso penal puede ser cauce para superar su 
daño, y sólo de manera secundaria toma como referencia al victimario. Lógicamente, con relación a este último, se trata también de un proceso útil socialmente, pues si la finalidad preponderante de la pena es la reinserción y la reeducación, si el condenado se implica personalmente en el proceso restaurativo, sin una finalidad utilitarista, se trabaja la empatía, siendo además posible en el curso de él la asunción de compromisos. Se desarrolla, de esta forma, una especial actitud que se proyecta tanto hacia la persona que fue objeto del daño intrínseco a la conducta delictiva, pero también hacia la comunidad personalizada en él, concienciación delictiva, con lo cual se incide en un elemento relevante resocializador.

En nuestro marco normativo no contamos con un completo desarrollo de la justicia restaurativa, pues la referencia recogida en la Ley 4/2015, del Estatuto de la víctima del delito, no ha sido objeto del imprescindible desarrollo reglamentario. Junto a esta referencia global, encontramos un nuevo elemento de justicia restaurativa en la mención al eventual condicionamiento de la suspensión de la condena al cumplimiento del acuerdo logrado en la mediación en el art. $84.1 \mathrm{CP}$; y en la pena de trabajos en beneficio de la comunidad del art. $49 \mathrm{CP}$, cuando se recoge la posibilidad de que estos consistan en labores de reparación de los daños causados o de apoyo o asistencia a las víctimas. Ya en la ejecución penitenciaria, tras la reforma del Código Penal operado por la LO $1 / 2015$, en uno de los supuestos privilegiados de la suspensión del resto de la pena y libertad condicional — supuesto de hasta 90 días de adelantamiento por año de cumplimiento adicional a las $2 / 3$ partes, una vez superada la mitad de la condena-, una nueva llamada se recoge a la justicia restaurativa en la consideración que se hace de la participación efectiva y favorable del penado en programas de reparación a las víctimas.

El Preámbulo ${ }^{16}$ del Estatuto afirma que aquél supera las referencias tradicionales a la mediación entre víctima e infractor y subraya la desigualdad moral que existe entre ambos, por lo cual la actuación de estos servicios se concibe orientada a la reparación material y moral de la víctima, y tiene como presupuesto el consentimiento libre e informado de la víctima y el previo reconocimiento de los hechos esenciales por parte del autor. Queda excluida, en todo caso, la posible actuación de los servicios de justicia restaurativa cuando ello pueda conllevar algún riesgo para la seguridad de la víctima o pueda ser causa de cualquier otro perjuicio.

$\mathrm{El}$ art. 15 del Estatuto ${ }^{17}$, establece expresamente este instrumento, a desarrollar a través de los servicios de justicia restaurativa, remitiéndose

16 Apartado VI, in fine.

17 «Artículo 15. Servicios de justicia restaurativa.

1. Las víctimas podrán acceder a servicios de justicia restaurativa, en los términos que reglamentariamente se determinen, con la finalidad de obtener una adecuada reparación material y moral de los perjuicios derivados del delito, cuando se cumplan los siguientes requisitos: 
la fijación de los términos concretos de aquéllos al desarrollo reglamentario, el cual, aún no se ha llevado a cabo.

Los servicios de justicia restaurativa se entenderían como un cauce apropiado para obtener una adecuada reparación material y moral de los perjuicios derivados del delito. Por lo demás, hay coincidencia en el contenido del precepto antes mencionado y el del art. 12 de la Decisión Marco 2001/220/JAI del Consejo, si bien la norma nacional contiene dos puntualizaciones, una relativa al victimario -que el infractor haya prestado su consentimiento- y otra al ámbito objetivo o material, en la medida que excluye la posibilidad de acudir a este mecanismo cuando esté prohibido por la Ley en alguna tipología específica — supuesto de la violencia de género-.

La recepción de la justicia restaurativa en el Estatuto de víctima respondería a la necesidad de encontrar soluciones satisfactorias para una adecuada reparación a aquélla de los daños derivados del delito. En este sentido, la mediación es un instrumento que puede contribuir a paliarlos por medio de la búsqueda de un espacio adecuado para la resolución de las necesidades de la víctima que no siempre se agotan en la obtención de una compensación de tipo pecuniario. La Ley, como anteriormente la Directiva 2012/29/UE, adoptan al respecto un perfil bajo, al tener un menor nivel de exigencia de su regulación penal frente a su predecesora, la Decisión Marco del Consejo 2001/220/JAI, pues no tendría carácter compulsivo para los Estados miembros, ni exigiría, siquiera, la toma en consideración de los acuerdos reparadores a que hayan llegado las partes, pues se limitaría a facilitar la derivación de casos penales, si procede, a los servicios de justicia reparadora, estableciendo al efecto las condiciones a observar en el procedimiento conforme a una serie de requisitos mínimos ${ }^{18}$.
a) el infractor haya reconocido los hechos esenciales de los que deriva su respon- sabilidad;
b) la víctima haya prestado su consentimiento, después de haber recibido infor- mación exhaustiva e imparcial sobre su contenido, sus posibles resultados y los procedimientos existentes para hacer efectivo su cumplimiento;
c) el infractor haya prestado su consentimiento;
d) el procedimiento de mediación no entrañe un riesgo para la seguridad de la víctima, ni exista el peligro de que su desarrollo pueda causar nuevos perjui- cios materiales o morales para la víctima; y
e) no esté prohibida por la Ley para el delito cometido.

2. Los debates desarrollados dentro del procedimiento de mediación serán confidenciales y no podrán ser difundidos sin el consentimiento de ambas partes. Los mediadores y otros profesionales que participen en el procedimiento de mediación, estarán sujetos a secreto profesional con relación a los hechos y manifestaciones de que hubieran tenido conocimiento en el ejercicio de su función.

3. La víctima y el infractor podrán revocar su consentimiento para participar en el procedimiento de mediación en cualquier momento».

18 C. ARANGÜEna FANEGO, "Protección y reparación de la víctima en la Unión Europea», en M.I. González CANo (dir.), Integración Europea y Justicia Penal, Valencia, Tirant Lo Blanch, 2018, pp. 155-159. 
Por lo que a la justicia restaurativa en la fase de ejecución se refiere, no hay mención alguna en la legislación estrictamente penitenciaria, LOGP y Reglamento de 1996. Sí la encontramos, sin embargo, con relación a la pena de prisión, en el Código Penal, que contempla en el art. 90.2 la participación favorable del penado en programas de reparación a las víctimas como actividad a valorar por el Juez de Vigilancia Penitenciaria a la hora de la concesión del adelantamiento de hasta 90 días adicional a la modalidad privilegiada a las $2 / 3$ partes.

Se recoge así la justicia restaurativa como un instrumento conectado a la reinserción del penado, favorecedor de ella en la medida en que la interiorización del daño causado coopera a tal fin y, en definitiva, a la asunción de valores prosociales. No obstante, por el contrario, su uso presenta como riesgo la posible disposición del penado a desarrollar esta actividad con un interés espurio, por lo cual, para no resultar aquél contraproducente, es preciso el desarrollo de un profundo trabajo por parte de los profesionales intervinientes en orden a detectar en el victimario su auténtico propósito.

Por un lado, tenemos que lo relevante desde el punto de vista penitenciario es la auténtica implicación personal del penado, con indiferencia de los logros en el desarrollo del programa, pues eso es algo que no depende de él, ni de su actitud. En definitiva, desde esta perspectiva lo interesante es el cambio que con esta técnica se produce en el sujeto, la sensibilización en cuanto a la conciencia por el mal causado, la empatía con la víctima, y todo ello como consideración de elemento positivo en su evolución.

Pero por otro, este eventual beneficio que obtiene el penado-victimario puede ser un inicial obstáculo desde la perspectiva de la víctima, pues de hecho supone un desplazamiento del centro de gravedad desde los intereses de ella a los de la persona que ha causado el daño.

En el ámbito de la pena de trabajos en beneficio de la comunidad, en su ejecución, el art. $49 \mathrm{CP}$ admite como posible contenido de estos la realización de «labores de reparación de los daños causados o de apoyo o asistencia a las víctimas, así como en la participación del penado en talleres o programas formativos o de reeducación, laborales, culturales, de educación vial, sexual y otros similares», con lo cual por este cauce cabe también introducir instrumentos restaurativos.

La ventaja que ofrece este precepto frente al supuesto de la libertad condicional es que aquí el contenido mismo de la pena pasa a ser la actividad reparadora, con lo cual no supone ninguna ventaja para el victimario.

Desde el punto de vista del cumplimiento de esta pena, la falta de implicación auténtica por parte del penado-victimario, como ocurre en todas las actividades que consisten en la realización de programas, es dudoso que pueda considerarse causa de quebrantamiento de condena, salvo 
que no acuda a las sesiones, dado el tenor del precepto. Esta conclusión, no impide que pueda entenderse que, aunque no medie quebrantamiento, el penado haya de completar las jornadas impuestas con otro contenido.

Desde una visión más amplia e inespecífica, podría decirse que elementos de la justicia restaurativa están presente en todas aquellas instituciones penitenciarias que hacen una valoración de la conducta - caso de las progresiones de grado, los permisos y la suspensión del resto de la pena y libertad condicional- y especialmente en la consideración del requisito relativo al pago de la responsabilidad civil a los efectos del acceso al tercer grado y la libertad condicional, art. 75.2 LOGP, en cuanto estimulo de la resocialización del victimario, incidencia en la reparación de la víctima y participación del elemento comunitario, lo cual posibilitaría la mediación ${ }^{19}$.

El Anteproyecto de Ley de Enjuiciamiento Criminal de 2020 contiene también una referencia en el art. 896 a la justicia restaurativa en la fase de ejecución, el cual establece que en si el condenado y la víctima manifiestan la voluntad de someter la ejecución a un procedimiento de justicia restaurativa, se procederá conforme a lo dispuesto al efecto en el art. $182^{20}$, el cual establece la regulación de aquél en las fases procesales previas; y de lograrse un acuerdo reparador, el Tribunal de Ejecución convocará una audiencia, si bien no está claro cual es el eventual efecto, ya que la remisión que se contiene al art. 895 se refiere a aquél acto a los efectos de resolver sobre las formas sustitutivas de las penas, el fraccionamiento de la multa, la ejecución de la responsabilidad civil o, en una cláusula abierta, cualquier otra cuestión relativa a la ejecución.

Hoy en día, sin embargo, ante la ausencia de desarrollo reglamentario que regule las posibilidades de los instrumentos reparadores, la participación de la víctima solo encuentra una satisfacción en el proceso penal en los elementos tradicionales, a saber, la responsabilidad civil o la imposición de la pena al culpable.

En la ejecución, la referencia en el ámbito de la libertad condicional a la participación del penado en estos programas como elemento a valorar a los efectos del eventual adelantamiento de aquélla, puede ser un importante punto de partida, si bien también supone un riesgo ante la posible concurrencia en el penado de un interés meramente utilitarista, de ahí la especial importancia de la labor del mediador en orden a detectar tal elemento distorsionador. En la regulación de este supuesto, además, se recoge la necesidad de ser oída la víctima, aunque no tenga derecho a ser parte en sentido estricto conforme al art. 13 del Estatuto,

19 C. Alonso Salgado, La mediación en el proceso penal, Valencia, Tirant Lo Blanch, 2017, pp. 303-309.

20 Este precepto se ubica en el Capítulo III del Título IV del Anteproyecto, que lleva por rúbrica La Justicia restaurativa. 
con carácter previo a la resolución, siempre que hubiere sido parte en la fase de enjuiciamiento.

En España, a pesar del difuso marco legal, no faltan experiencias en esta materia. La más conocida es, quizás, la denominada Vía Nanclares, con los internos de la banda terrorista ETA.

La SGIP, desde el año 2018 ha implantado el Programa Diversidad, destinado a internos que voluntariamente quieran desarrollarlo y a condenados a penas y medidas alternativas, en este caso con carácter obligatorio, el cual tiene por objeto la intervención contra xenofobia, homofobia y otros delitos de odio a través del tratamiento psicoeducativo. El programa desarrolla en cuatro fases: evaluación, intervención, seguimiento y, por último, justicia restaurativa ${ }^{21}$.

Desde finales de 2019, promovido por el CGPJ, Fiscalía General y la SGIP, se ha iniciado una nueva experiencia con el fin de elaborar un Protocolo al efecto. Tal tarea se desarrollaría en el establecimiento penitenciario de Burgos; en los establecimientos penitenciarios de Sevilla, en colaboración con la Fiscalía Provincial; y, por último, en el CIS «Máximo Carrera» de Valladolid, en este caso con la colaboración del Juzgado de Vigilancia de Castilla y León $\mathrm{n}^{\mathrm{o}} 1$.

Se trata así de generalizar un nuevo modelo de justicia, en el cual la mediación, se convierte, en palabras de Cervelló Donderis ${ }^{22}$, en un instrumento para propiciar el diálogo entre agresor y víctima para que, guiados por un mediador imparcial, sean capaces de llegar a un acuerdo reparador satisfactorio para ambas partes.

\section{Contenido del programa piloto}

\subsection{Operadores}

La puesta en marcha de la justicia restaurativa en la fase de ejecución penitenciaria encuentra un primer problema en el estrecho marco regulador constituido, como ya se ha expuesto, por la referencia contenida en el Estatuto de la Víctima a los servicios al efecto y las menciones del Código Penal, tanto la relativa al eventual contenido de la pena de trabajos en beneficio de la comunidad, como a la modalidad privilegiada de la suspensión del resto de la pena y libertad condicional. Falta un cauce normativo preciso al que acudir para llevar a la práctica tan generales enunciados.

21 http://www.institucionpenitenciaria.es/web/portal/Noticias/Noticias/noticia_0400. html [Consulta 27/04/2020].

22 V. CERVElló Donderis, «La justicia restaurativa en la reforma penal», Cuadernos Digitales de Formación, CGPJ, n 33, 2014. 
Estas someras referencias, sin embargo, no han impedido llevar a cabo diversas experiencias, una de ellas el Proyecto piloto que tiene sus orígenes en el año 2019, a desarrollar en el CIS «Máximo Carrera» de Valladolid, con la entidad AMEE (Asociación para la Mediación, el Encuentro y la Escucha) y la participación del Juzgado de Vigilancia Penitenciaria $\mathrm{n}^{\circ} 1$ de Castilla y León. En la actualidad se ha iniciado la andadura de su segunda edición.

El objetivo de este Proyecto es claro, desarrollar un protocolo de actuación que permita hacer extensivo el instrumento de la justicia restaurativa a los demás centros penitenciarios, tomando como referencia, en este caso, el medio abierto y situaciones de libertad, de ahí que se haya elegido para su implantación un Centro de Inserción Social (CIS). Es en esta clase de establecimientos penitenciarios donde se lleva a cabo el seguimiento de estos elementos penales de ejecución en las fases últimas de ella. Al propio tiempo, es en el CIS donde se ubica el Servicio de Gestión de Penas y Medidas Alternativas (SGPMA), el cual se encarga, entre otras funciones, de la puesta en marcha y control de la pena de trabajos en beneficio de la comunidad.

Con este Proyecto se trata de evaluar las posibilidades de la justicia restaurativa como instrumento de satisfacción de la víctima, que es el objetivo principal, en conexión con la finalidad esencial de la sanción penal y de la propia Institución Penitenciaria, la reeducación y reinserción social del penado, art. $25 \mathrm{CE}$ y art. 1 de la LOGP y $2 \mathrm{RP}$, pero trabajado con los victimarios en un momento avanzado de cumplimiento.

Esta perspectiva, el trabajo con sujetos que ya han alcanzado importantes metas en el objetivo resocializador de la pena, ofrece como ventaja un menor riesgo de actitudes manipuladoras por parte de aquéllos, pues desarrollar ahora la empatía no les reporta especiales ventajas en el iter penitenciario.

La razón de la intervención del Juzgado de Vigilancia Penitenciaria en este Programa encuentra su apoyo normativo tanto en la mención del art. $90 \mathrm{CP}$, en el ámbito de la libertad condicional, como en la del art. 49 $\mathrm{CP}$, referida ésta al control de la pena de trabajos en beneficio de la comunidad. En definitiva, es este órgano judicial el que en última instancia realiza la valoración de las actividades desplegadas por el penado a la hora de la concesión de la libertad condicional, en el primer caso, y la adecuación de la actividad incluida en el Plan de Ejecución de la pena de trabajos en beneficio de la comunidad, en el segundo.

Pero esta participación va mucho más allá, toma como apoyo la referencia del Estatuto de la Víctima y la necesidad de intervención de una autoridad pública que tiene acceso a una información, la víctima, la cual no está al alcance de los mediadores, ni siquiera, en ocasiones, de la Administración penitenciaria. 
Precisamente el primer obstáculo a salvar sería la Ley Orgánica 3/2018, de 5 de diciembre, de Protección de Datos Personales y garantía de los derechos digitales, pues no cabe una cesión de los de las víctimas sin su anuencia, datos que son imprescindibles para poder contactar con ellas. Es aquí donde la labor de Juzgado se torna imprescindible y en la cual, a través de la Oficina Judicial, se va a llevar a cabo el punto de interconexión, con un escrupuloso y cuidado respeto de la posición de la víctima, como luego se expondrá.

El Programa se desarrolla con penados en tercer grado, liberados condicionales y personas condenadas a la pena de trabajos en beneficio de la comunidad. El perfil elegido tiene la ventaja de que por el momento penitenciario de cumplimiento de la pena o la naturaleza de la pena misma, no tiene sentido para el condenado perseguir finalidad utilitarista alguna, pues su participación en este programa no le reporta beneficio en cuanto a su situación penal, simplemente es muestra de una implicación en su tarea de responsabilización por la conducta infractora y exteriorización de la empatía hacia el perjudicado por el delito, elementos ambos que forman parte de la ardua labor reinsertadora.

\subsection{Fases}

\subsubsection{Fase de responsabilización por el delito cometido}

El proceso se inicia con una primera fase de selección de los penadosvictimarios por parte del Centro Penitenciario, que en definitiva es quien tiene un contacto directo y mayor conocimiento de ellos.

A continuación, el personal de AMEE lleva a cabo una preselección, en la que se incluyen a aquellos victimarios que se considera están preparados para pasar a la segunda fase de reparación y para el encuentro con sus respectivas víctimas de los hechos.

En la primera edición del programa se ha trabajado exclusivamente con víctimas directas, si bien de futuro se consideran otras opciones.

Esta preselección realizada por la Entidad mediadora, sus resultados, se comparten con el director del Centro Penitenciario, la subdirectora del Centro de Inserción Social y el Juez de Vigilancia Penitenciaria, en orden a evaluar el pase a la siguiente fase del proceso de los penados seleccionados.

4.2.2. Fase de reparación y de encuentro con la víctima del delito

Una vez hecha la evaluación antes mencionada, por parte del director del Centro Penitenciario, se enviaron los respectivos oficios al 
Juez de Vigilancia Penitenciaria, al objeto de que el mismo facilitara el envío de unas cartas en las que se invitaba a las víctimas a una primera entrevista informativa sobre el proceso de justicia restaurativa en las dependencias judiciales.

Estas cartas, aunque remitidas por el Juzgado a las víctimas y, por tanto, un cauce oficial, no responden en su redacción al típico formato y lenguaje procesal, antes bien se trata de reflejar y ofertar en ellas, con una redacción próxima y amable, un nuevo servicio para aquellas víctimas que tengan una necesidad de reparación que va más allá de la mera sanción penal como consecuencia del proceso. Se destaca además la total ausencia de cualquier compulsión para participar en el Programa, pues el protagonista y quien decide es la víctima. Al tiempo, se ofrece, si tienen dudas, y antes de avanzar en el proceso restaurativo, la posibilidad de ponerse en contacto con el Juzgado para explicarles el objeto de la misiva, pues hay que tener muy claro que para la población en general el contacto con la Justicia, más la penal, tiene un cierto contenido estresante. En definitiva, se puede decir que se trata de mostrar una cara amable del sistema de justicia.

La redacción de estas cartas se ha hecho con la participación tanto AMEE, como del CGPJ y del propio Juzgado.

La primera misiva remitida se acompaña de un folleto explicativo elaborado por la SGIP y el CGPJ, en el cual se expone qué es la justicia restaurativa.

En caso de falta de respuesta de la víctima, se repite el proceso una segunda vez, si se estima necesario, en este caso remitiendo otro texto en el cual se expone la posibilidad de contactar directamente con la entidad mediadora, para lo cual se le facilitan los datos de aquella.

En caso de existir disposición de la víctima para una primera toma de contacto, se organiza una sesión informativa individualizada con cada una de las víctimas interesadas, sesiones a la que asisten los miembros de AMEE y el propio Juez.

Si la víctima se muestra de acuerdo con el proceso restaurativo, es cuando con su consentimiento se ceden los datos a la entidad mediadora, la cual, a partir de entonces, va a trabajar con ella en varias reuniones en orden a la preparación de la fase de reparación y encuentro víctimavictimario, si es que es posible.

\subsubsection{Encuentro restaurativo y demás opciones}

Aunque el objetivo del programa es el encuentro de víctima y victimario, caben además otras opciones, como puede ser la remisión de una carta de arrepentimiento por parte del victimario, que solo se cursa si la víctima consiente, o, incluso, una conducta más general por parte de 
aquél, como es participar en actividades de concienciación (charlas en colegios...), como parte de su compromiso reparador.

\subsection{Resultados de la primera edición}

Los penados-victimarios elegidos para participar en el programa, tras la valoración inicial, que tuvo lugar en febrero de 2020, fueron cinco. En cuanto a las víctimas directas, las potenciales beneficiarias del programa, se contaba con once.

En la tipología considerada se incluyó delitos de robo violento, robo con fuerza, detención ilegal, violencia en el ámbito familiar y atentado. Se excluyó un supuesto de impago de pensiones.

La primera remesa de cartas enviadas por parte del Juzgado tuvo lugar a finales de febrero de 2020, obteniéndose respuesta satisfactoria de cuatro víctimas, que mostraron su interés en participar en el Programa: dos víctimas de un mismo victimario por delito de malos tratos en el ámbito familiar; y otras dos víctimas, Policías Locales, de otro victimario por delito de atentado.

Las cuatro víctimas acudieron a la sesión informativa que tuvo lugar en las dependencias al efecto de la Audiencia Provincial de Valladolid.

En cuanto a las restantes víctimas:

- Una de ellas comunicó al Juzgado su no interés en participar en el Programa dado el tiempo transcurrido, entendiendo que ya tenía superada la situación.

- Otra de las víctimas comunicó al Juzgado que no querían participar al no residir en Valladolid en la actualidad.

- Tras la segunda misiva, remitida en marzo, una de las víctimas contactó directamente con AMEE, comunicando que se consideraba resarcida y agradecía la propuesta.

- Cuatro víctimas no contestaron ni a la primera, ni a la segunda de las misivas.

En cuanto a los resultados del Programa, en el caso de uno de los victimarios — robo con fuerza-, su víctima no quiso acceder al encuentro con el autor, aunque comunicó su agradecimiento por la iniciativa. El victimario, ya que tendría pagada la responsabilidad civil, habría escrito una carta a la víctima, pidiéndose desde asociación el consentimiento a aquélla para poder remitírsela, siendo esta su manera concreta de reparar el daño causado. También habría mostrado su disposición a impartir charlas preventivas en colegios y acercarse a colectivos vulnerables para reparar el daño causado. 
En el caso de uno de uno de los victimarios condenado por un delito de violencia en el ámbito familiar, se logró llevar a cabo un encuentro con una de sus víctimas, hermana de aquél, de cara a expresarle su arrepentimiento por los hechos cometidos. Con la otra víctima, también hermana, no fue posible celebrarlo por motivos laborales de ésta que le impedían acudir a aquél.

Por último, en el caso del victimario condenado por un delito de atentado, una de las víctimas habría llegado a participar en un encuentro restaurativo, si bien la otra, aunque habría participado en las sesiones preparatorias, por motivos personales, habría rechazado la opción.

\section{Conclusiones}

\subsection{Ventajas}

Hay que se conscientes que el modelo a establecer en el Protocolo, como en realidad la potencialidad de la justicia restaurativa, no es un modelo de masas, es un instrumento de limitado alcance, que parte de la total individualización y predisposición de los implicados, víctima y victimario.

El diseño inicial en el que se está trabajando es un instrumento centrífugo en el sentido que va desde la Institución penitenciaria, identificación del penado susceptible de ser uno de los actores en el proceso restaurativo, hacia fuera, pues el segundo momento es la búsqueda y contacto con la víctima en aras a un eventual encuentro futuro.

Es, por otro lado, un modelo universal en el sentido de que busca servir para cualquier tipología delictiva, tanto infracciones de escasa entidad, como aquellas otras en que se lesionan bienes jurídicos más relevantes. No hay más exclusiones por el objeto que las expresamente derivadas de la norma, caso de la violencia de género.

Es un modelo polivalente en cuanto a su meta, pues, como en todo proceso restaurativo, el ideal objetivo es el encuentro con la víctima, también admite otros logros, como puede ser una carta de arrepentimiento o participación en actividades de participación comunitaria por parte del victimario, lo cual tiene la ventaja de dar una dimensión comunitaria a la experiencia, al implicar a la propia sociedad en el proceso.

No es un modelo premial, pues con la participación del victimario éste no obtiene recompensa alguna por su intervención en la experiencia, lo cual excluye el peligro de un uso utilitarista. Esto se logra tanto por el momento en el cual se desarrolla el proceso restaurativo, como por el hecho de que no es el victimario el protagonista, antes bien, el objetivo fundamental es dar satisfacción a la víctima, a sus necesidades, miedos e inquietudes, allí donde no llega la pena. 
Otra nota a destacar es la flexibilidad, pues el modelo quiere adaptase a las circunstancias de cada caso, tanto en el procedimiento de contacto con la víctima, como en la consecución de los objetivos. E incluso en la forma concreta de llevarse a cabo las sesiones con la víctima, que se adaptan a su disponibilidad laboral, familiar o de otra índole, intentando causarle los menores perjuicios posibles en su vida cotidiana.

Por último, aunque es un tema secundario, el modelo coopera y trabaja la empatía del victimario con la víctima, lo que incide en el proceso resocializador del primero.

\subsection{Déficits}

El programa, tanto en la primera, como en la segunda edición, está diseñado desde la Institución penitenciaria a la víctima. De futuro, se está planteando, vía asociaciones de víctimas o el Ministerio Fiscal, contactar con las víctimas en primer lugar, para luego ver las posibilidades de reparación trabajando con el victimario.

La buena marcha de estos programas depende en gran medida de la buena voluntad de los distintos operadores: Entidad, Administración y Juzgado.

\section{Bibliografía}

Acale Sánchez, M., «Terrorismo, delincuencia organizada y sistema de penas», en P. Faraldo Cabana (dir.), L.M. Puente Alba, y J.A. BranDARIZ GARCía (coords.), Nuevos retos del Derecho Penal en la era de la globalización, Valencia, Tirant Lo Blanch, 2004.

Alonso Salgado, C., La mediación en el proceso penal, Valencia, Tirant Lo Blanch, 2017.

ARAngüena Fanego, C., «Protección y reparación de la víctima en la Unión Europea», en M.I. GonZÁlEz CANO, (dir.), Integración Europea y Justicia Penal, Valencia, Tirant Lo Blanch, 2018.

ARmenta Deu, T., «Justicia restaurativa, mediación penal y víctima. Vinculación europea y análisis crítico», Revista General de Derecho Europeo, no 44, 2018.

Botero MARTínez, J.L., «Justicia restitutiva, retributiva y estructural en el contexto de la profecía bíblica», Reflexiones Teológicas, nº 10, 2012.

Castañón Álvarez, M.J. y Solar Calvo, M.P., «Estatuto de la víctima: consideraciones críticas a la nueva Ley 4/2015», Diario La Ley, n 8685, 2016.

CERvelló Donderis, V., «La justicia restaurativa en la reforma penal», Cuadernos Digitales de Formación, CGPJ, nº 33, 2014. 
GIL GIL, A., «Sobre la satisfacción de la víctima como fin de la pena», Indret: Revista para el Análisis del Derecho, nº 4, 2016.

Landrove Díaz, G., La moderna Victimología, Valencia, Tirant Lo Blanch, 1998.

RENART GaRcía, F., «Del olvido a la sacralización. La intervención de la víctima en la fase de ejecución de la pena (Análisis del art. 13 de la Ley 4/2015, de 27 de abril, del Estatuto de la víctima del delito, a la luz de la L.O. 1/2015, de 30 de marzo, de modificación del Código Penal)», Revista Electrónica de Ciencia Penal y Criminología, no 17-14, 2015.

Soleto MuÑoz, H., «La justicia restaurativa, mecanismo adecuado para mejorar la reparación a la víctima en el proceso penal», Justicia Restaurativa y mediación penal, Cuadernos Digitales de Formación, CGPJ, $\mathrm{n}^{\mathrm{o}} 17,2017$. 